\title{
Study on BIM Technology Teaching Under The Background of Three-dimensional Design
}

\author{
Xiaobiao Lv $^{1, a}$, Yanyan Huang ${ }^{1, b}$, Yiquan Zou ${ }^{1, c}$ \\ ${ }^{1}$ School of civil engineering and architecture, Hubei University of Technology \\ Wuhan City, Hubei Province, China 430068 \\ alvxiaobiaohn@163.com, bhuangyianyian@sina.com, 'zyq124@126.com
}

Keywords: BIM technology, teaching method, curriculum system, architectural design

\begin{abstract}
In the past 20 years, computer-aided design (CAD) technology enabled architects and structural engineers getting rid of manual drawing, greatly improved work efficiency. In recent years, as the emergence and popularity of informational architectural design, BIM (Building Information Modeling) technology has greatly promoted the three-dimensional architectural design and construction of a three-dimensional, which have become a hot field of development field of building design and construction. Thus, teaching practice and innovation of BIM technology have flourished at many colleges and universities nationwide. In view of the current problems existing in BIM teaching, this paper explored BIM teaching methods and models which combined architectural design courses. Based on practice and thinking in the teaching process in BIM Technology, the author summarized the teaching mode which improved students' comprehensive use of BIM technology and established the concept of three-dimensional architectural design.
\end{abstract}

\section{Introduction}

In the past 20 years, computer-aided design (CAD) technology enabled architects, structural engineers getting rid of manual drawing, greatly improved work efficiency. However, CAD is not radical departure from the idea of drawing by hand. People's lack of efficiency in the process of building the information processing of the information transmission and processing, greatly hindered the construction industry to improve production efficiency.

With the increasing development of Internet and computer technology in recent years, BIM (Building Information Modeling) technology as the representative of the information technology has become an extremely important part of the development of modern building industry. In the future, applied to IPD (Integrated Project Delivery - Integrated Project Delivery), VDC (Virtual Design \& Construction - Virtual design and construction), parametric building design and green construction and other fields, BIM will bring great social benefits of social, economic and environmental benefits. China has put BIM into the "Twelfth Five-Year" plan, the BIM standard is of forthcoming implementation. Nowadays, the teaching practice and innovation for BIM technology are in the booming in many colleges and universities.

\section{Status of BIM Technology in Teaching}

As current BIM technology teaching practice and exploration are in the initial stages, many university's BIM courses and teaching methods are essentially based on the CAD and other courses to develop. These colleges and universities, using the traditional computer operating practice skills teaching, tend to BIM courses as computer technology courses, so BIM Technology Courses are without fusion of Architectural design courses. Thus, BIM courses are not considered for the logic relation between architectural form, space, function of the combination of architectural design. This teaching model greatly increases the difficulty to enable students to grasp and use of BIM technology for the three-dimensional visualization design, in particular to enable students to set up three-dimensional architectural design concept.

Hubei University of Technology(HBUT) architecture started earlier in BIM teaching, since 
2007, our teaching team introduced a new revised undergraduate syllabus and training plan. Through curriculum system construction, with the system of the syllabus and training program, our teaching system for BIM to be improved. Our teaching team currently has 27 teachers, not only in computer-related courses for teachers, many teachers are also engaged in architectural design courses related to BIM. Since 2011, we implemented the first multi-disciplinary collaborative BIM graduate design, achieved good teaching results, including two architecture graduates received provincial outstanding graduate design. After several years of teaching practice, we have done a lot of research on the teaching mode and method of BIM technology courses. In 2012 February, we built "BIM teaching innovation base", which has become the Hubei University of Technology teaching reform and innovation practice side window.

\section{The Construction of Curriculum System and Teaching Method Reform}

Construction of Curriculum System. Since 2007 Bachelor, Architecture in Hubei University of Technology has implemented the new revised syllabus and training programs. Through curriculum system construction, we scattered in the doors of the original architectural design courses on the three-dimensional computer-aided design, combined BIM and parametric design teaching content, integrated into the courses of "Computer Aided Architectural Design 1,2,3". Closely integrated architectural design courses, we Architecture first grade, second grade, third grade next semester have opened BIM curriculum. Teaching major BIM software covered Autodesk Revit Architecture, Rhino3D, Autodesk Revit MEP, etc, and have established a relatively standardized teaching requirements and teaching achievement requirements.

BIM technology emphasis on design, construction and management of all aspects of close collaboration, learning of the curriculum of each sub-module level complex content is of great difficulty. As a dedicated BIM undergraduate courses, only three BIM courses of "Computer Aided Architectural Design1,2,3", probably due to a long time without using BIM technology environment, students would forget or be inconsistent with BIM technology. Since 2011, we implemented the first multi-disciplinary collaborative BIM graduate design, achieved good teaching results, including two architecture graduates received provincial outstanding graduate design. 2012, 2013 summing up the first session of the basis of experience, we continue to insist on the implementation of a multi-disciplinary collaborative BIM graduate design, and has gradually worked out a set of relatively standardized, effective teaching methods and training mode.

Teaching Method Reform. Aim to highlighting the subject role of the students learning, our unit strengthened the training of teaching and practice in BIM, reformed the course content, teaching method. We established the teacher-student interaction of persistent, open architecture BIM teaching mode, thus students became the main body in the course teaching. In addition, for each BIM course work results, we support the students' own planning, organizing public exhibitions.

In "Computer Aided Architectural Design -2" course, for example, the main learning content as Autodesk Revit Architecture, the course was a big job this software as the main body, expanding the study and practice into other software to learn and use. Student's learning process was divided into three phases:

(1) Found a modern classic small villa information to determine a modeling design case.

(2) Primarily used Autodesk Revit software, combined with the use of Auto CAD, Sketch up, V-Ray, Lumion, Photoshop and other software, complete modern villa of the late pre-modeling and rendering.

(3) Student exported renderings and typesetting production of display panels, publicly displayed and exchanged experience sharing (Fig 1), public assessment of the teacher talk, inviting industry experts to interact(Fig 2). 


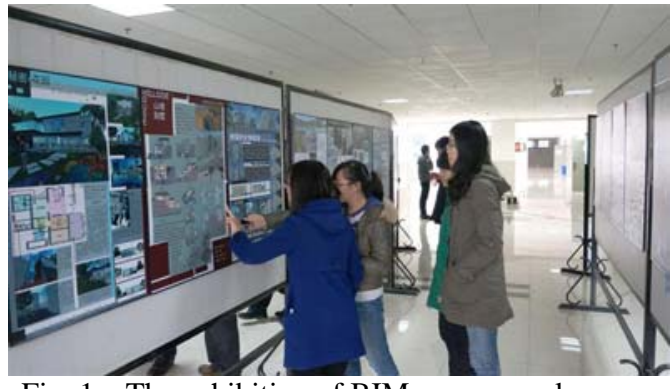

Fig. 1 The exhibition of BIM course work

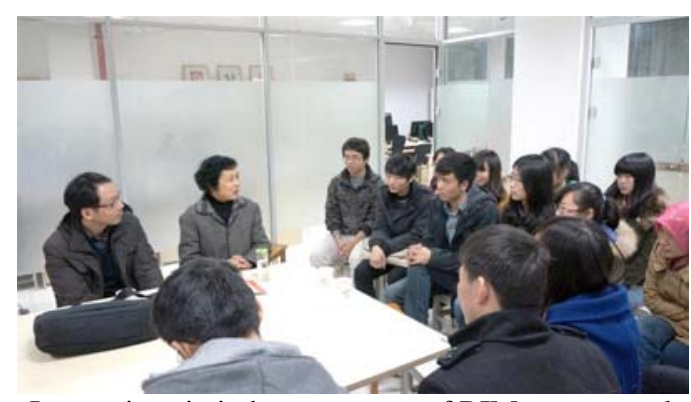

Fig. 2 Interactions in industry experts of BIM course work exhibition

\section{Relying on the "BIM teaching innovation base" in Practice of BIM technology Projects}

In addition to a fairly standard BIM classroom work, we rely the "BIM teaching innovation base" platform for BIM teaching methods and training model study, which combines a multi-disciplinary collaborative graduate design, technological innovation and entrepreneurship, project engineering practice. Since the beginning of 2012, combined with the National Collegiate technological innovation and entrepreneurship project reporting, we "BIM teaching innovation base" Team teachers organized students into several groups, from different directions, seeking to declare the subject areas of BIM. There are already four projects implemented successfully entered the running state reporting, specifically including the projects of "Alien overrun architectural complex digital design technology development and services", "Hubei University campus Google Earth Modeling", "BIM technology-based architectural renovation project in the pipeline secondary put into use ", " foreign ancient classical architectural 3D digital simulation". In 2013, there are a number of student groups BIM projects being declared also.

April 2012, by the National Steering Committee for Higher architecture disciplines organized, AUTODESK company-sponsored, Huazhong University of Science Co, Hubei University of Technology "BIM teaching innovation base" contractors "BIM-based architectural design teacher training" caused widespread impact on BIM education industry(Fig 3). The BIM teacher training, not only to cultivate BIM faculty, and improving teaching quality BIM, while showcasing the BIM Hubei University of Technology in the field of teaching reform achievements.

\section{Innovation of BIM teaching method combined with the science and technology competition for College Students}

Since 2010, we have continuously BIM team teachers organize students to participate in "Higher Education Cup" National Undergraduate advanced mapping and product information modeling Innovation Competition, "Revit Cup" National College Sustainable Building Design Competition, made a number of competition achievements, encouraging the majority of teachers and students teaching and learning initiative. In 2012, Donghua University in Shanghai, at the Fifth "Higher Education Cup" National Undergraduate advanced mapping and product information modeling Innovation Competition, our university got groups first prize and individual all-around prize (Fig. 4 ).

According to students training course design work for Science and technology competition, project work practice, competitions winning achievements, course handouts and textbooks written results, we have compiled data compilation of teaching for the future reform of teaching methods. 


\section{Summary}

Currently, the teaching practice and innovation of BIM technology has been booming in many Chinese universities, Hubei University of Technology architecture is also active in research and practice of BIM teaching. After several years practice of BIM teaching and scientific research, we have done a lot on the teaching mode and methods of BIM, achieved some initial results, and accumulated a lot of valuable experience. Aiming at solving the problems existing in current BIM technology teaching, on the basis of practice and thinking in the BIM teaching, the author summarized the close combination of architectural design course and BIM courses to improve
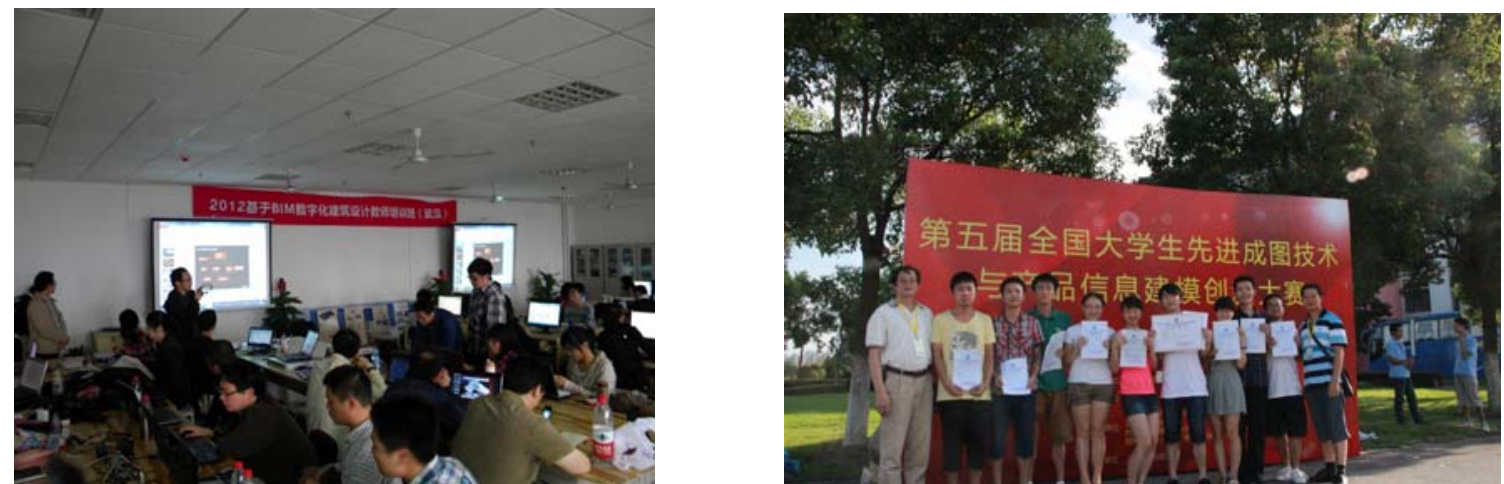

students' comprehensive application of the BIM technique, and to develop the ability to participate in scientific and technological innovation under the background of three-dimensional design, hoping to other teachers, who engaged in BIM Curriculum Teaching, have some reference value.

\section{References}

[1] Xiaobiao Lv, Yiquan Zou, Yanyan Huang: The 3D Coordinated Building Design Based on Building Information Modeling. Advances in Civil Engineering and Architecture(Part 7):6587-6591(2012)

[2] Xiaobiao Lv: Discussion of the Architectural Construction Courses in Close Connection with the Architectural Design. Journal of Architectural Education in Institutions of Higher Learning, Vol.20(2011),p. 86

[3] Yanyan Huang, Xiaobiao Lv: The Architectural Design Strategies of Low Carbon Economy. Journal of Hubei University of Technology,Vol.5(2011),p121

[4] Xiao Fu: From 2D to 3D: BIM in Building Design. World Architecture,Vol.9(2006),p153

[5] Yousheng Deng , Xiaobiao Lv : introduction to civil engineering, Peking University Press, 2012.7 